DOI: https://doi.org/10.15688/nav.jvolsu.2020.1.13

UDC 930.26

Submitted: 19.03 .2020

LBC 63.4(2)

Accepted: 29.04 .2020

\title{
MIDDLE PALEOLITHIC SITE SUKHAYA MECHËTKA: THE RENEWAL OF COMPLEX INVESTIGATIONS ${ }^{1}$
}

\author{
Aleksander K. Otcherednoy \\ Institute for the History of Material Culture RAS, Saint Petersburg, Russian Federation
}

Stanislav O. Remizov

Historical, Ethnographic and Architectural Museum-Preserve «Old Sarepta», Volgograd, Russian Federation

\section{Ksenia N. Stepanova}

Institute for the History of Material Culture RAS, Saint Petersburg, Russian Federation

\section{Maxim V. Eltsov}

Institute of Physicochemical and Biological Problems in Soil Science RAS, Pushchino, Russian Federation

\section{Ekaterina V. Voskresenskaya}

Institute of Geography RAS, Moscow, Russian Federation

\section{Leonid B. Vishnyatsky}

Institute for the History of Material Culture RAS, Saint Petersburg, Russian Federation

\section{Pavel E. Nehoroshev}

Institute for the History of Material Culture RAS, Saint Petersburg, Russian Federation

\section{Egor K. Blochin}

Institute for the History of Material Culture RAS, Saint Petersburg, Russian Federation

\section{Vadim V. Titov}

Southern Scientific Center of the RAS, Rostov-on-Don, Russian Federation

\author{
Aleksander V. Kolesnik \\ Donetsk National University, Donetsk, Ukrain
}

\begin{abstract}
The Sukhaya Mechëtka site, located on the northern outskirts of Volgograd, has attracted the attention of Paleolithic researchers since its discovery in 1951 by geologists A.I. Koptev and M.N. Grishchenko. The materials of the site - a collection of stone products currently kept at the MAE RAS, and chronostratigraphic information - can be considered as perfect by standards of open Paleolithic complexes. To a large extent, the site acquired such a significance due to the presence of the only one perfectly preserved cultural layer, which lies in clear stratigraphic conditions. Being densely overlapped with thick deposits, the site was preserved so well that it remained unaffected
\end{abstract}


by the turbulent natural processes of the last glacial-interglacial macrocycle. Single-layer sites usually have a disadvantage comparing to multi-layer complexes in terms of the importance level of the tasks solved with their help. But the Sukhaya Mechëtka favorably differs from other sites by the measure of cultural layer being studied in the field and the potential for further studies. The stone assemblage and field documentation archives created by M.Z. Panichkina and S.N. Zamyatnin show a picture of the life of Middle Paleolithic hunters settlement taken at limited time interval. It is confirmed by preliminary results of planigraphic and technological analyzes performed with use of refitting. Sukhaya Mechëtka is a practically intact echo of an individual Neanderthal community's life, as far as it's possible for archaeological material of this age. However, the matter of the site's chronology, and the time period of Sukhaya Mechëtka layer formation being determined in particular, are not completely resolved. The representations of the middle of the last century based on geological observations (Mikulino) need to be verified. The $\mathrm{C}^{14}$ dating method showed obviously an inadequately young age. OSL dating results are expected to be gained in the future.

Key words: Middle Paleolithic, Late Pleistocene, Sukhaya Mechëtka, neanderthal, Micoquian, buried soils, Khazarian transgression of the Caspian Sea, Khvalynian transgression of the Caspian Sea.

Citation. Otcherednoy A.K., Remizov S.O., Stepanova K.N., Eltsov M.V., Voskresenskaya E.V., Vishnyatsky L.B., Nehoroshev P.E., Blochin E.K., Titov V.V., Kolesnik A.V., 2020. Middle Paleolithic Site Sukhaya Mechëtka: the Renewal of Complex Investigations. The Lower Volga Archaeological Bulletin, vol. 19, no. 1, pp. 230-253. (in Russian). DOI: https://doi.org/10.15688/nav.jvolsu.2020.1.13

\section{СРЕДНЕПАЛЕОЛИТИЧЕСКИЙ ПАМЯТНИК СУХАЯ МЕЧЁТКА: ВОЗОБНОВЛЕНИЕ КОМПЛЕКСНЫХ ИССЛЕДОВАНИЙ ${ }^{1}$}

\section{Александр Константинович Очередной}

Институт истории материальной культуры РАН, г. Санкт-Петербург, Российская Федерация

\section{Станислав Олегович Ремизов}

Историко-этнографический и архитектурный музей-заповедник «Старая Сарепта», г. Волгоград, Российская Федерация

\section{Ксения Николаевна Степанова}

Институт истории материальной культуры РАН, г. Санкт-Петербург, Российская Федерация

\section{Максим Витальевич Ельцов}

Институт физико-химических и биологических проблем почвоведения РАН,

г. Пущино, Российская Федерация

\section{Екатерина Владимировна Воскресенская}

Институт географии РАН, г. Москва, Российская Федерация

\section{Леонид Борисович Вишняцкий}

Институт истории материальной культуры РАН, г. Санкт-Петербург, Российская Федерация

\section{Павел Евгеньевич Нехорошев}

Институт истории материальной культуры РАН, г. Санкт-Петербург, Российская Федерация

\section{Егор Константинович Блохин}

Институт истории материальной культуры РАН, г. Санкт-Петербург, Российская Федерация

\section{Вадим Владимирович Титов}

Южный научный центр РАН, г. Ростов-на-Дону, Российская Федерация 
Middle Paleolithic Site Sukhaya Mechëtka: the Renewal of Complex Investigations

\section{Александр Викторович Колесник}

Донецкий национальный университет, г. Донецк, Украина

Аннотация. Стоянка Сухая Мечётка, расположенная на северной окраине Волгограда, привлекает внимание исследователей палеолита со времени своего открытия в 1951 г. геологами А.И. Коптевым и М.Н. Грищенко. Материалы памятника - коллекция каменных изделий, хранящаяся в МАЭ РАН, и хроностратиграфическая информация - могут считаться эталонными для среднепалеолитических комплексов открытого типа. В немалой степени такое значение памятник приобрел вследствие наличия только одного прекрасно сохранившегося культурного слоя, залегающего в ясных стратиграфических условиях. За счет плотных перекрывающих отложений большой мощности памятник оказался законсервирован настолько хорошо, что остался не затронут бурными природными процессами последнего ледниково-межледникового макроцикла. Однослойные памятники обычно проигрывают многослойным комплексам по степени фундаментальности решаемых на них задач. Но Сухая Мечётка выгодно отличается от других стоянок степенью изученности культурного слоя в полевых условиях и тем потенциалом для дальнейшего изучения, который еще может быть реализован. Коллекции инвентаря и архивы полевой документации, созданные М.З. Паничкиной и С.Н. Замятниным, демонстрируют картину жизни поселения охотников среднего палеолита в течение ограниченного временного интервала, что подтверждается предварительными результатами планиграфического и технологического анализов с применением ремонтажа: Сухая Мечётка - это практически неизмененный слепок жизни отдельного неандертальского сообщества, насколько это возможно для археологического материала такого возраста. Однако именно вопросы хронологии и времени формирования слоя Сухой Мечётки являются не вполне решенными. Представления середины прошлого века, основанные на геологических наблюдениях (Микулино), нуждаются в проверке, $\mathrm{C}^{14}$ метод датирования показал, очевидно, омоложенный возраст, в перспективе - получение ОСЛ дат.

Ключевые слова: средний палеолит, поздний плейстоцен, Сухая Мечётка, неандертальский человек, микок, погребенные почвы, хазарская трансгрессия Каспия, хвалынская трансгрессия Каспия.

Цитирование. Очередной А. К., Ремизов С. О., Степанова К. Н., Ельцов М. В., Воскресенская Е. В., Вишняцкий Л. Б., Нехорошев П. Е., Блохин Е. К., Титов В. В., Колесник А. В., 2020. Среднепалеолитический памятник Сухая Мечётка: возобновление комплексных исследований // Нижневолжский археологический вестник. Т. 19, № 1. C. 230-253. DOI: https://doi.org/10.15688/nav.jvolsu.2020.1.13

Стоянка Сухая Мечётка является одним из важнейших памятников среднего палеолита Восточной Европы (рис. 1,1), в этом регионе с ним по значимости может быть сопоставлена, пожалуй, только Ильская стоянка. Не каждый из памятников Центральной и Восточной Европы сможет сравниться с этими стоянками по степени выразительности индустрий, культурных слоев и влиянию, оказанному на развитие палеолитоведения. Однако на этом сходство их судеб заканчивается. Если к раскопкам Ильской неоднократно возвращались разные поколения исследователей, то раскопки Сухой Мечётки были молниеносно организованы, проведены с привлечением крупных строительных организаций и не возобновлялись до сих пор. Если коллекции многослойной Ильской до сих пор не изучены целиком, и, кроме того, частично дестратифицированы, то коллекции единственного культурного слоя Сухой Мечётки были изданы уже через семь лет после завершения работ [Замятнин, 1961]. В общем история изучения па- мятника складывалась удачно, что подробно представлено в монографии Н.Д. Праслова и Л.В. Кузнецовой, посвятивших изучению стоянки много лет [Праслов, Кузнецова, 2020]. Двухлетняя кампания раскопок в начале 50-х гг. прошлого века привлекла широкое внимание отечественных и зарубежных археологов, а отдельные части коллекций были несколько раз опубликованы в различных крупных обобщающих работах [Bosinski, 1967; Праслов, 1984; Кузнецова, 2000; 2006]. Сухая Мечётка была открыта во время геологических изысканий при строительстве Волжской ГЭС и изучена на широкой площади более чем в $650 \mathrm{~m}^{2}$ за два года благодаря активной помощи руководства стройки, этим стоянка не отличается от десятков других палеолитических памятников, обнаруженных при спасательных работах в Сибири и Европейской части страны в 50-70-е гг. прошлого века. Однако расположение Сухой Мечётки на окраине крупного и активно развивающегося областного центра повлияло на включенность этой территории в 
городскую застройку и хозяйственное освоение, и, как следствие, на степень доступности памятника для дальнейших работ.

Памятник расположен на правом берегу глубокой древней одноименной балки, прорезающей правый берег долины Волги на северной окраине Волгограда (микрорайон Спартановка - северная часть Тракторозаводского района города) (рис. 1,2, 2). Топография правого берега Волги здесь сильно усложнена возвышенное правобережье изрезано глубокими субпараллельными балками, впадающими в Волгу в широтном простирании, заложение их относится к послехвалынскому времени и происходило оно, вероятно, по более древним, дохвалынским, балкам [Праслов, Кузнецова, 2020, с. 17]. В большинстве этих балок уже после открытия стоянки в Сухой Мечётке были зафиксированы палеолитические местонахождения, сырьем для которых в каждом случае служат местные выходы кремня и кварцита. Это позволяет считать северную оконечность города, а также все правобережье реки в Дубовском и Камышинском районах крайне перспективным регионом на Нижней Волге для поисков стратифицированных памятников различных эпох палеолита [Реми3ов, 2019, с. 188, 189].

Балка Сухая Мечётка разрезает хвалынскую террасу на северной окраине Волгограда, которая тянется вдоль приводораздельных участков Приволжской возвышенности, сложенных в верхней части ергенинскими отложениями, почти до Мамаева Кургана (рис. 1,2). Долина балки хорошо выработана в рельефе (рис. 2,1, 5,1,2), ее ширина составляет в разных местах от 100 до 250 м. Строение балки по обоим бортам примерно одинаковое: снизу вверх последовательно выделяются толщи хазарских песков, ательских суглинков, включающих серию гидроморфных погребенных почв, и отложения хвалынской трансгрессии Каспия [Праслов, Кузнецова, 2020, с. 25]. Русло, выработанное в позднехвалынское время, разрезало и морские хвалынские отложения, и подстилающие их ательские отложения, в том числе и палеолитическую стоянку. Памятник приурочен к небольшому мысу, хорошо выраженному еще в 70-е гг. прошлого века и выступавшему в долину Сухой Мечётки менее чем в ста метрах к востоку от железнодорожного моста на бетонных опорах (рис. 2, 3), который был возведен в непосредственной близости от памятника в начале 1950-х годов (рис. 4). К железнодорожному полотну подходит ул. Академика Богомольца, в конце которой располагается Пассажирское автотранспортное предприятие (ПАТП). Во время строительства ПАТП уровень дневной поверхности бровки правого борта балки в районе локализации памятника был дополнительно поднят насыпью. Вся правая часть памятника в 1980-е гг. была застроена многоярусным гаражным кооперативом (рис. 3, 4, 5,1,2). И лишь в 2010 г. между тыльным забором ПАТП и бровкой был поставлен памятный знак, информирующий о расположении в пределах данной территории памятника археологии федерального значения и предупреждающий об ответственности за несанкционированную хозяйственную деятельность. Однако ко времени установки знака площади, непосредственно примыкающие к изученной территории памятника Сухая Мечётка, уже подверглись значительному воздействию, и в той или иной степени оказались вовлечены в активную хозяйственную деятельность, сопровождавшую развитие города.

\section{Основные этапы исследования памятника}

Местонахождение каменных орудий, приуроченных к культурному слою в овраге, прорезающем правый борт балки Сухая Мечётка, было открыто геологами А.И. Коптевым и М.Н. Грищенко в августе 1951 года. Подъемный материал сразу же был отвезен в Костёнки, где был продемонстрирован С.Н. Замятнину и А.Н. Рогачеву, и в ноябре того же года С.Н. Замятнин вместе с аспирантом ИИМК А.А. Формозовым для проверки материалов А.И. Коптева и М.Н. Грищенко прибыли в Сталинград. Раскопки памятника были начаты в следующем 1952 г. и продолжены с перерывом на год в 1954 году. В первый же год были заложены два раскопа по обеим сторонам оврага, разделяющего памятник на две части. После окончания первого полевого сезона толща перекрывающих отложений была разрыхлена при помощи двух направленных взрывов. В 1954 г. изучение 
культурного слоя было продолжено уже на более широкой площади - в итоге было вскрыто около $650 \mathrm{~m}^{2}$ по обеим сторонам оврага. Материалы этих исследований, которые до сих пор остаются единственными масштабными работами на памятнике, были опубликованы в 1961 г. в 82-м выпуске КСИА [Замятнин, 1961, с. 5-37; Чигуряева, Хвалина, 1961, с. 37 42; Громов, 1961, с. 42-48]. Строительство опор железнодорожного моста велось параллельно с раскопками.

Через пятнадцать лет после завершения работ С.Н. Замятниным, в 1969 г., Н.Д. Праслов для уточнения датировки памятника предпринял попытку вскрытия одной из стенок первых раскопов. Организовать работы на памятнике сразу не удалось, и повторная попытка была предпринята Н.Д. Прасловым в 1979 г., когда был специально организован Волгоградский палеолитический отряд, основной целью работ которого было комплексное изучение разрезов Сухой Мечётки. Участниками этих работ были заложены 6 разрезов по периметру предполагаемых площадей, вскрытых раскопами С.Н. Замятнина. Все разрезы были описаны, были отобраны образцы на различные виды анализов, в частности, образцы для установления характеристик погребенных почв, полная колонка образцов для палинологического анализа [Праслов, Кузнецова, 2020, с. 25, 26]. Результаты этих работ оставались неопубликованными в течение почти сорока лет.

В 1974 г. памятник Сухая Мечётка был поставлен на охрану постановлением Совета Министров РСФСР № 624 от 04.12.1974 года. Тем не менее, несмотря на документальное подтверждение наличия охранной зоны на площади стоянки, выявленной работами С.Н. Замятнина и Н.Д. Праслова, в начале 1980-х гг. на правом борту балки было начато строительство многоуровневого гаражного кооператива, занявшего, в частности, всю правую часть памятника (рис. $3,4,5,1,2$ ). При строительстве гаражей рельеф правой части небольшого мыса, на котором был локализован памятник, претерпел значительные изменения. Кроме того, при выравнивании площадки под строительство ПАТП, расположенного по ул. Академика Богомольца, оказался полностью засыпанным овраг, разделявший памятник на правую и левую части (рис. 3). Выравнивание площадок для строительства ПАТП и гаражного кооператива привело к тому, что те участки памятника, которые, по мнению его первых исследователей, были перспективны для дальнейшего изучения культурного слоя стоянки, оказались перекрыты толщей привезенного грунта мощностью от двух до десяти и более метров. Таким образом, на протяжении сорока лет, фактически с момента открытия, рельеф местности на памятнике был подвергнут неоднократным масштабным изменениям. В 2010 г. при составлении нового паспорта на объект культурного наследия федерального значения «стоянка Сухая Мечётка (Волгоградская)» охранная зона вокруг предполагаемых внешних границ раскопов С.Н. Замятнина была расширена до 150 метров (рис. 4).

Основная причина возобновления работ на Сухой Мечётке состоит в том, что на протяжении шестидесяти лет памятник фактически был исключен из активного исследовательского процесса: данные, собранные экспедицией С.Н. Замятнина, нуждаются в уточнении на фоне активно развивающегося в последние десятилетия изучения хроностратиграфии разрезов с лессово-почвенными и морскими отложениями Каспийского бассейна в регионе Нижней Волги и Ахтубы (например: [Свиточ, 2008; 2015; Салтыков, 2011; Янина, 2012; Лаврушин и др., 2014; Янина и др., 2014; 2017; Бадюкова, 2015; Безродных и др., 2015]). Результаты работ экспедиции под руководством Н.Д. Праслова были опубликованы только в начале 2020 г., в рамках начала нового этапа исследования этой уникальной стоянки. Между тем памятник до сих пор является единственной в России среднепалеолитической стоянкой открытого типа, единовременно вскрытой на значительной площади. По данным С.Н. Замятнина, культурный слой памятника залегает in situ, на памятнике были выявлены следы хозяйственной активности в виде структуры, состоящей из пяти кострищ и нескольких зон различной деятельности. Кроме того, один из видов двусторонне обработанных орудий, обнаруженных в культурном слое памятника, после работ Г. Бозинского стал эпонимным для названия одного из наиболее ярких типов в категории асимметричных обушковых ножей (кайльмессеров) - Wolgogradmesser или нож волгоградского типа [Bosinski, 1967, S. 59, 
60], отличающихся удлиненностью, сегментовидной формой и отсутствием протяженного естественного обушка.

Таким образом, материалы памятника вызвали широкий резонанс в литературе по среднему палеолиту Европы. Итак, памятник выделяется по меньшей мере хорошей сохранностью культурного слоя, его распространением на значительной площади, многочисленным и выразительным каменным инвентарем, особенностями распределения различных зон активности, прослеженными на этапе раскопок.

Одной из причин возвращения к работе с материалами Сухой Мечётки является возобновление комплексного исследования среднепалеолитических памятников Русской равнины группой, состоящей из специалистов Отдела палеолита ИИМК РАН и Лаборатории эволюционной географии ИГ РАН. Для полноценного сравнительного анализа данных, полученных в течение последних лет на отдельных стратифицированных памятниках Восточной Европы, необходимо использование материалов синхронных памятников с близкими характеристиками условий залегания и степени сохранности, а также изученных при помощи единого набора методов. Начало этим работам было положено исследованиями группы стратифицированных памятников среднего палеолита на Верхней Десне (Хотылёво I и Бетовская группа памятников), и, кроме Сухой Мечётки, к работе привлечены многослойные памятники Бирючья Балка-2 и Рожок I, расположенные соответственно в нижнем течении Северского Донца и в береговом обрыве северного побережья Азовского моря (рис. 1,1). Возобновление исследований Сухой Мечётки (в рамках Нижневолжской экспедиции ИИМК РАН), таким образом, является одной из стадий реализации единого проекта по обновлению аналитических данных по стратифицированным среднепалеолитическим памятникам Русской равнины.

\section{Современный этап исследования}

Полевые работы на памятнике были возобновлены в 2014 г. - в первую очередь был снят топографический план участка балки, непосредственно примыкающего к памятнику, который учитывает все изменения релье- фа местности, произошедшие за последние сорок лет (рис. 2, 3). Кроме того, на основании ортофотоснимка была создана трехмерная модель участка балки, на котором расположен памятник. На модель в дальнейшем может быть спроецирована вся имеющаяся информация о стратиграфии осадочных отложений в районе памятника, а также информация о строении участков, вскрытых при дальнейшем исследовании стоянки.

Для получения наиболее полной стратиграфической информации о четвертичных отложениях, подстилающих и перекрывающих культурный слой памятника, рядом с западной стенкой Раскопа I (Западного раскопа) С.Н. Замятнина [Замятнин, 1961, с. 9, рис. 2; Праслов, Кузнецова, 2020, с. 92, рис. 8], был заложен разрез, постепенно доведенный до современной бровки мыса (рис. 5,2, 6,1,2,7). Из-за значительной мощности отложений было принято решение сформировать полный разрез из отдельных ярусов - крупных врезок в правый борт балки в западной части мыса, к которому приурочен памятник. Всего было сформировано пять ярусов, пронумерованных римскими цифрами от I - заложенный от дневной поверхности - до $\mathrm{V}$ - наиболее глубокого, вскрывающего культурный слой и подстилающие его отложения. Вся хроностратиграфическая информация о памятнике базируется на изучении этого разреза (он обозначен как Разрез СМ 14-18) (рис. 6,1). Общая мощность отложений, вскрытых разрезом, составляет 26 м при общей мощности отложений мыса в 36 метров. Разрез не доведен до основания борта балки из-за массива отвалов 1952 и 1954 гг., для удаления которых необходимо использовать технику.

Окончательная интерпретация разреза соотнесение различных выделенных толщ с хвалынскими, ательскими и хазарскими отложениями - будет проведена позднее. Однако предварительные данные свидетельствуют в пользу того, что хвалынские отложения, содержащие в значительном количестве Dreissena polymorpha, представлены в данном разрезе только в его кровле (рис. 7) (по всей видимости, литологические слои 5-9), ниже следует мощная пачка ательских суглинков (предположительно, литологические слои 13-29), которая подстилается толщей хазарских отложений 
Middle Paleolithic Site Sukhaya Mechëtka: the Renewal of Complex Investigations

(вскрыта только их кровля, в которой выделены литологические слои 30-32). В нижней части ательской толщи выделяется серия погребенных почв и, вероятно, уровней эфемерного почвообразования (литологические слои 21, 23, $24,25,27)$. К наиболее выразительной почве (литологический слой 25) привязан культурный слой памятника.

Во время работ по углублению разреза ни в одном из литологических слоев артефакты обнаружены не были, однако в слоях 21, 23 и 32 были встречены фаунистические находки: мелкие фрагменты трубчатых костей (литологический слой 21), фрагмент трубчатой кости с эпифизом и несколько зубов, вероятно, принадлежащих северному оленю (литологический слой 23). При работах в нижней части Разреза СМ 14-18 была, в частности, обновлена и зачищена кровля песчаной толщи, ассоциируемой с хазарскими песками (литологические слои 30-32 по описанию 2018 г.). При углублении дна яруса V в литологическом слое 32 была обнаружена тазовая кость Bison priscus (определение В.В. Титова), залегавшая в оглеенном сизом прослое ожелезненных песков (рис. 10,1,2). Находка залегает на 1,7 м ниже погребенной почвы, ассоциируемой с культурным слоем. Положение находки в пределах вскрытой площади - субгоризонтальное. В пятнадцати сантиметрах к В от тазовой кости был зафиксирован мелкий древесный уголек. Другие находки на вскрытой площади обнаружены не были. Учитывая неоднократные факты обнаружения фаунистических остатков (единичных костей) в отложениях, перекрывающих уровень культурного слоя Сухой Мечётки, данная находка также может быть расценена как единичная находка фауны.

Единственное изделие из кремня было обнаружено при зачистке восточной стенки разреза на уровне литологического слоя 25 (культурного слоя памятника), прорезавшего нижнюю часть склоновых рыхлых отложений, отождествляемых с отвалом Западного раскопа 1954 г. С.Н. Замятнина. Это небольшой фрагмент пластинчатого кремневого скола без проксимальной части с мелкой однорядной чешуйчатой ретушью по правому краю дорсальной поверхности (рис. 9). Цвет кремня (коричневато-бежевый с бурыми и коричневы- ми прослоями) полностью соответствует характеристикам местного карбонового кремня из ергенинских песков, которые считаются источником кремневого сырья, использовавшегося обитателями стоянки Сухая Мечётка.

Морфологические характеристики дорсальной поверхности изделия свидетельствуют в пользу плоскостного принципа расщепления. Взаимное расположение негативов может также указывать на то, что этот пластинчатый отщеп являлся сколом второго скалывания («enlèvement deux», что предполагает леваллуазское расщепление). Даже беглый обзор его характеристик демонстрирует принадлежность обнаруженного орудия к среднему палеолиту. Поэтому, скорее всего, изделие было пропущено при разборке культурного слоя в начале 50 -х годов.

С единственным культурным слоем Сухой Мечётки ассоциируется литологический слой 25 - это плотный темно-серый (местами черный) гумусированный суглинок с многочисленными включениями мелких и средних угольков (в том числе сохранивших структуру древесины) и золистыми линзами (имеющими форму пятен), а также вторичными карбонатными новообразованиями. Слой сильно нарушен червеходами, по которым в него затащен материал из вмещающих слоев, и также материал, слагающий слой, проникает в нижележащий. Мощность литологического слоя на вскрытом участке составляет до $20 \mathrm{~cm}$.

Поверхность этого суглинка была расчищена в прирезке площадью $6 \mathrm{~m}^{2}$, расположенной к В от основного разреза (рис. 8). На поверхности слоя были обнаружены золистоуглистые скопления в виде окрашенных древесным углем линз. Наиболее крупные из угольков, около 1 см, были отобраны для вероятного получения AMS дат. На всей вскрытой площади золистость концентрировалась в пятна диаметром от 10-15 до 40 см. Изделий из камня и фаунистических остатков обнаружено не было, за исключением единственного мельчайшего фрагмента неопределимой кости. Принадлежность этих скоплений к культурному слою, изученному С.Н. Замятниным, несомненна. В пользу этого свидетельствуют следующие факты: 1) литологические характеристики слоя 25 - структура погребенной 
почвы, ее цвет и мощность на данном участке, полностью отвечающая описанию С.Н. Замятнина погребенной почвы с культурным слоем; 2) насыщенность литологического слоя мелкими угольками и золистостью; 3) обнаружение единственного неопределимого фрагмента кости именно на поверхности этой погребенной почвы, что соответствует описанию положения находок С.Н. Замятниным. Первые два пункта также полностью соответствуют описаниям культурного слоя Сухой Мечётки в западной части стоянки (Раскопе I), оставленным С.Н. Замятниным [Замятнин, 1961, с. 8, 9] и Н.Д. Прасловым [Праслов, 1984, с. 107; Праслов, Кузнецова, 2020, с. 28, 29]. Косвенными свидетельствами могут считаться обнаружение участков склона, отождествляемых с отвалами западного раскопа С.Н. Замятнина, а также обнаружение пластинчатого скола с ретушью в отвале 1954 года.

По образцам гумуса из погребенной почвы, вмещающей культурный слой, к настоящему времени получены две радиоуглеродные даты: $34700 \pm 900$ (ГИН-15608) и $39500 \pm 800$ (ГИН-15198а) [Очередной и др., 2018, с. 78; Otcherednoy et al., 2019, p. 314; Вишняцкий, Нехорошев, Очередной, 2019, с. 79, 80]. Полученные даты, видимо, не отражают реальный возраст памятника и являются значительно омоложенными. Рассматривать их как доказательство позднего возраста Сухой Мечётки не стоит. Работа по получению серий хронометрических данных продолжается - из разреза были отобраны также образцы для ОСЛ датирования, результаты которого ожидаются в ближайшее время.

Углисто-золистые скопления, обнаруженные на вскрытом участке литологического слоя 25, могут быть связаны как с антропогенным фактором, так и с насыщением палеопочвы древесным углем в результате естественных процессов. Однако такие скопления, обнаруженные на площади прирезки 2015 г., распределены по вскрытому участку неравномерно - они сконцентрированы в восточной части прирезки и фактически уходят далее на восток к площадям, вскрытым западным раскопом С.Н. Замятнина в 1954 году. Этот факт свидетельствует в пользу принадлежности углисто-золистых скоплений к участкам культурного слоя Сухой Мечётки, который был также неравномерно насыщен подобными скоплениями. По свидетельству С.Н. Замятнина, такие скопления были связаны с пятнами обнаруженной им линии очагов, в таком случае можно предполагать, что скопления 2015 г. как-то связаны с объектами, изученными ранее.

Таким образом, в разрезе был обнаружен и разобран участок нижней погребенной почвы Сухой Мечётки. Факт принадлежности этого участка к культурному слою памятника ясен, а отсутствие находок каменных изделий и фаунистических остатков свидетельствует лишь в пользу того, что разрез и прирезка вскрыли западную периферийную часть стоянки. Согласно планам распространения находок, впервые опубликованным М.3. Паничкиной в КСИА № 82, плотность находок падает в западной части площади, вскрытой в 1954 году. В восточной части памятника культурный слой, по мнению С.Н. Замятнина, также был выбран полностью. Единственным перспективным направлением для дальнейших исследований культурного слоя памятника является вскрытие новых площадей к югу от участков, вскрытых в 1954 году. Однако это связано с необходимостью привлечения техники для удаления 22-метровой толщи перекрывающих отложений. Проведение подготовительных мероприятий такого масштаба вполне возможно, но при планировании любых крупных работ на памятнике необходимо учитывать, что в непосредственной близости от стоянки находятся объекты городской инфраструктуры (участок двухколейной электрифицированной дороги, связывающей Российскую Федерацию с регионами Центральной Азии, действующий железнодорожный мост, ПАТП, гаражный кооператив), и провести предварительное согласование предполагаемых мероприятий с соответствующими ведомствами.

\section{Перспективы исследований}

Внимание к памятнику, как ключевому объекту для изучения не только культурных особенностей среднего палеолита Европы, но и важному, а в перспективе и опорному геоархеологическому комплексу для хроностратиграфических реконструкций различных 
Middle Paleolithic Site Sukhaya Mechëtka: the Renewal of Complex Investigations

этапов трансгрессий Каспия и экологических изменений на протяжении последнего ледниково-межледникового макроцикла в юго-восточных регионах Восточно-Европейской равнины, должно быть поддержано его скоординированным междисциплинарным изучением различными группами исследователей. В августе 2018 г. Разрез СМ 14-18 был продемонстрирован участникам Международной конференции - полевого семинара Loessfest, которая периодически проходит в различных областях Европы и Азии и посвящена изучению лессово-почвенных серий различных регионов континента. Вместе с несколькими геологическими разрезами Ахтубы, Сухая Мечётка стала объектом для демонстрации участникам семинара [Kurbanov et al., 2018], что может послужить возвращению памятника в научный оборот на современном уровне.

Следующие стадии изучения Сухой Мечётки (рассчитанные на первую половину 2020-х гг.) будут связаны с получением новых аналитических данных. Параллельно проводится изучение коллекции Сухой Мечётки, находящейся на постоянном хранении в МАЭ РАН. Полевые работы на памятнике должны быть продолжены и будут связаны с расширением площади изучения различных литоло- гических слоев в пределах остатков мыса, на котором расположена стоянка.

\section{Благодарности}

Коллектив авторов выражает признательность коллегам и жителям Волгограда, без помощи которых работы были бы невозможны - М.В. Кривошееву (ВолГУ, г. Волгоград), А.С. Лапшину (ВГСПУ, г. Волгоград), Д.Е. Жукову (ВолГУ, г. Волгоград), М.А. Стрельникову (ВолГУ, г. Волгоград), Г.О. Кидиной (г. Волгоград). Мы также благодарны коллегам, оказавшим помощь в работах по подготовке и интерпретации разреза на Сухой Мечётке, И.А. Идрисову (Институт геологии Дагестанского научного центра РАН, г. Махачкала), В.А. Бурлаку (ИА АН Молдавии, г. Кишинев) и А.М. Киселевой (ИИМК РАН, г. Санкт-Петербург).

\section{ПРИМЕЧАНИЕ}

1 Работа выполнена в рамках программы ФНИ ГАН по теме государственного задания № 0184-2019-0001.

The research was carried out within the Fundamental Research of State Academies of Science on the theme of state assignment no. 0184-2019-0001. 


\section{ИЛЛЮСТРАЦИИ}

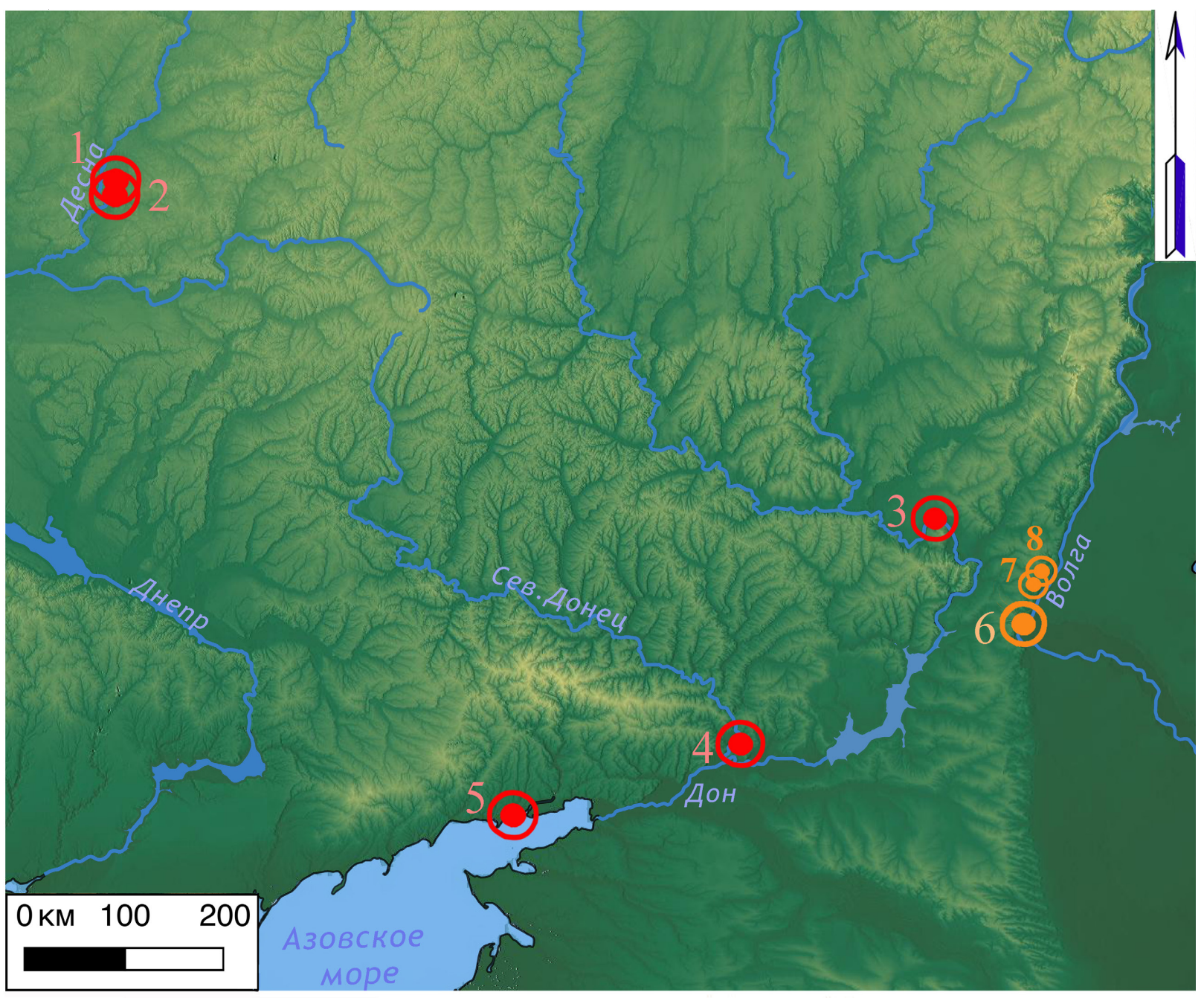

Условные обозначения:

- многослойные памятники

- однослойные памятники

Рис. 1. Отдельные стратифицированные среднепалеолитические памятники Восточной Европы, расположенные на Верхней Десне (1 - Бетово; 2 - Хотылёво I); Среднем Дону (3 - Шлях);

Нижнем Дону (4 - Бирючья Балка-2); Северном Приазовье (5 - Рожок I);

Нижней Волге (6 - Сухая Мечётка; 7 - Заикино Пепелище; 8 - Челюскинец)

Fig. 1. Single stratified Middle Paleolithic sites of Eastern Europe located on the Upper Desna (1-Betovo; 2 - Khotylevo I); Middle Don (3 - Shlyah); Lower Don (4 - Biryuchaya Balka-2), Northern Azov Sea littoral (5 - Rojok I); Lower Volga (6-Sukhaya Mechëtka; 7-Zaikino Pepelistche; 8-Chelyuskinets) 


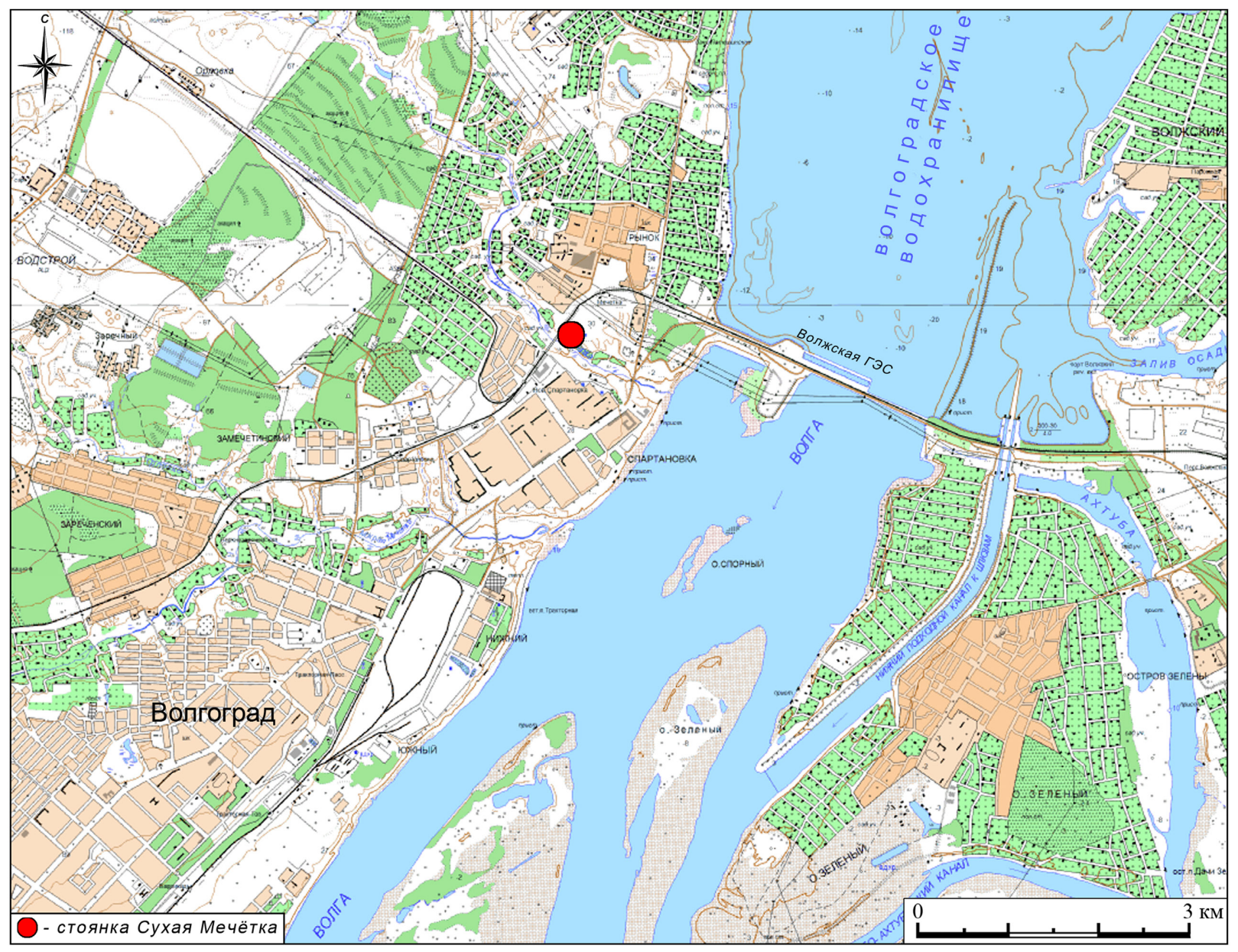

Рис. 1. Окончание:

2 - место расположения памятника Сухая Мечётка на северной окраине г. Волгограда (микрорайон Спартановка Тракторозаводского района)

Fig. 1. End:

2 - location of the site Sukhaya Mechëtka on the northern outskirts of Volgograd (the Traktorozavodsky district) 


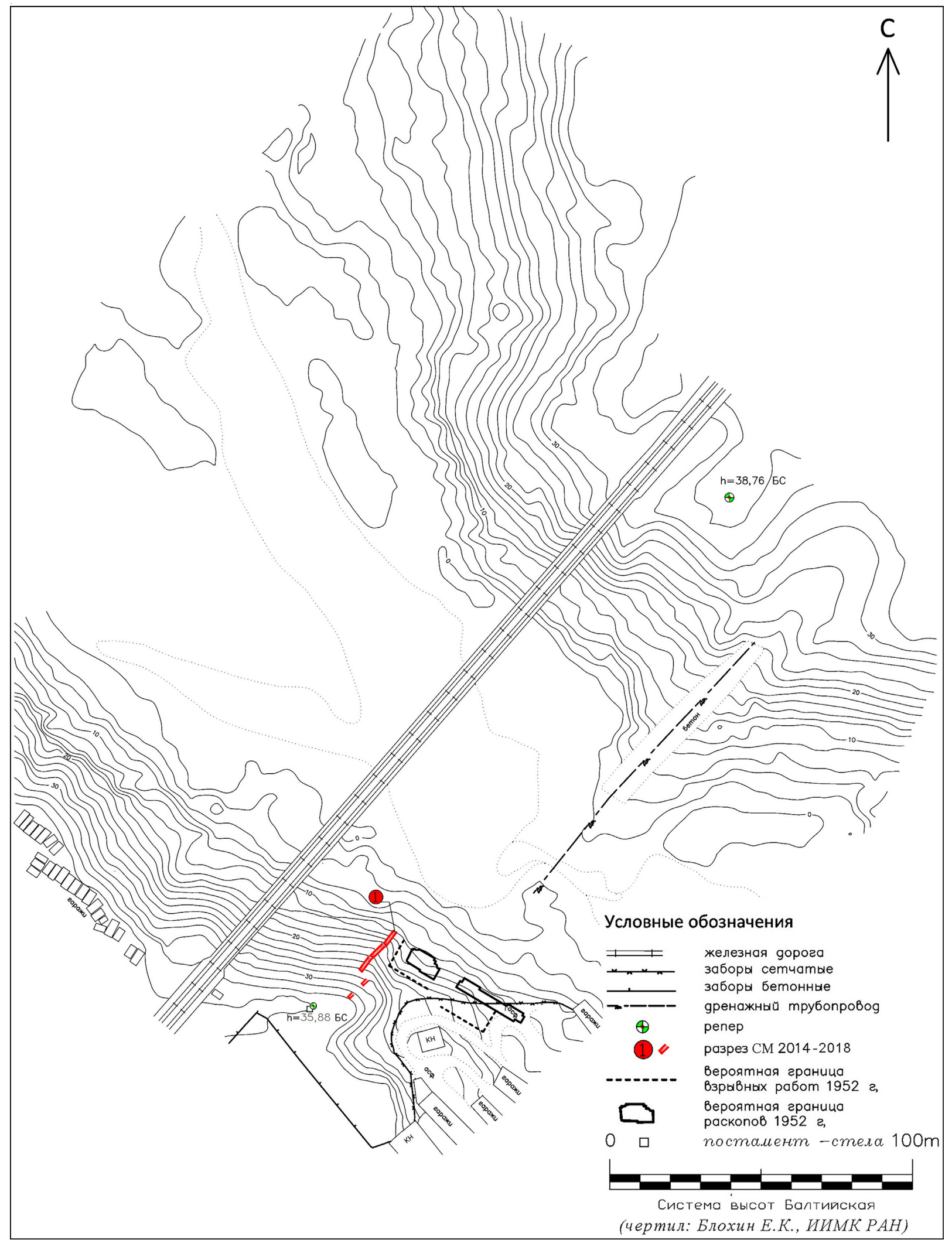

Рис. 2. Место расположения памятника Сухая Мечётка на северной окраине г. Волгограда (микрорайон Спартановка Тракторозаводского района)

Fig. 2. Location of the site Sukhaya Mechëtka on the northern outskirts of Volgograd (the Traktorozavodsky district) 
Middle Paleolithic Site Sukhaya Mechëtka: the Renewal of Complex Investigations

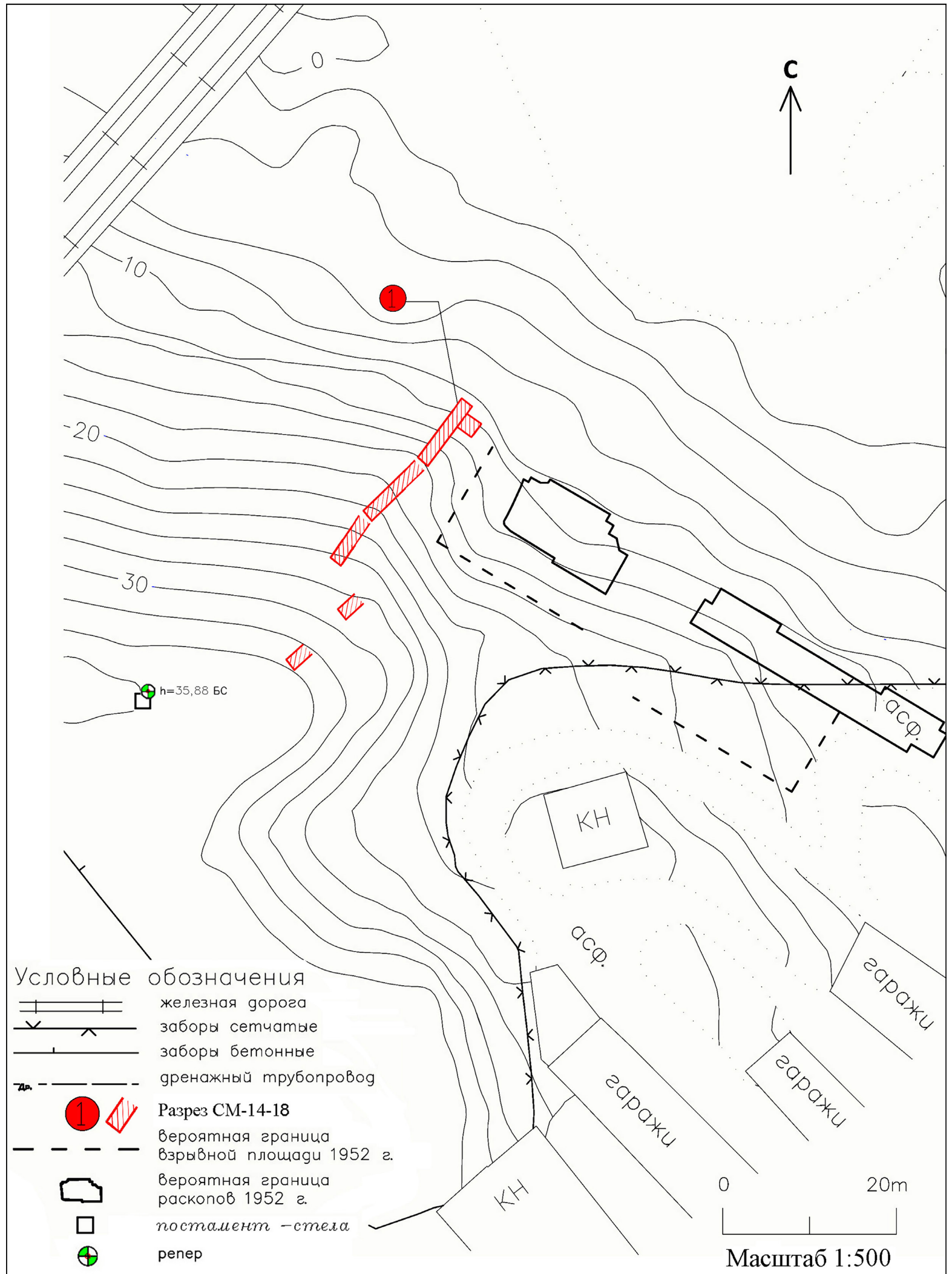

Рис. 3. Сухая Мечётка. Расположение разреза СМ 14-18, прирезки 2015 г. и вероятное расположение площадей памятника, вскрытых раскопами 1952 и 1954 годов. Масштаб 1:500 (чертеж Е.К. Блохина)

Fig. 3. Sukhaya Mechëtka. The location of the SM 14-18 section, 2015 Trench, and likely location of the site's areas, excavated by the trenches of 1952 and 1954. Scale 1:500 (drowing by E.K. Blochin) 


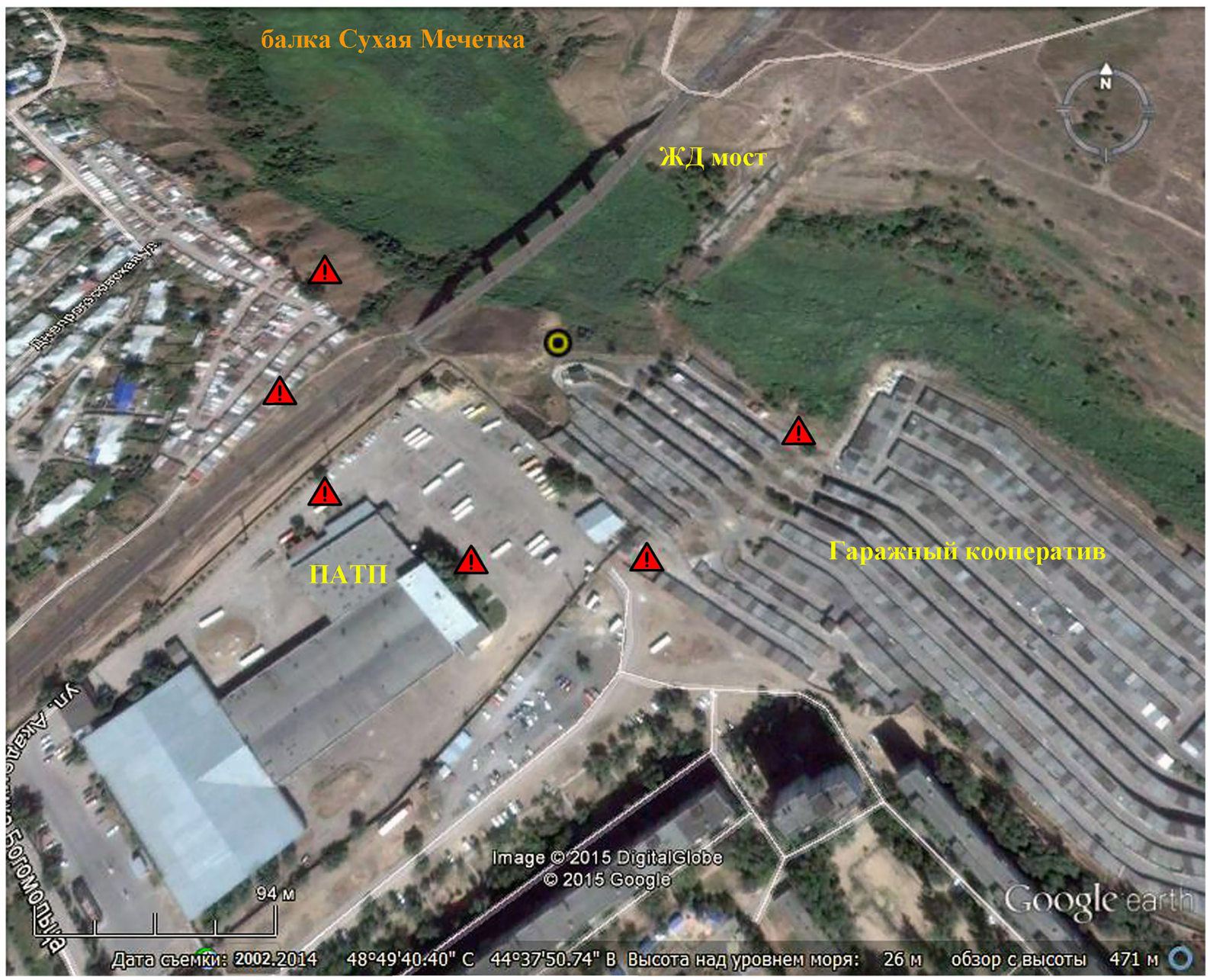

Условные обозначения: (-уччасток памятника, выявленный С.Н. Замятниным $\$ - границы охранной зоны

Рис. 4. Сухая Мечётка. Место расположения памятника Сухая Мечётка на северной окраине г. Волгограда (северная граница микрорайона Спартановка Тракторозаводского района).

Современный вид памятника и границы охранной зоны, установленные в 2010 году

Fig. 4. Sukhaya Mechëtka. The location of the site Sukhaya Mechëtka on the northern outskirts of Volgograd. The modern view of the site area and the boundaries of the protected zone established in 2010 
Middle Paleolithic Site Sukhaya Mechëtka: the Renewal of Complex Investigations
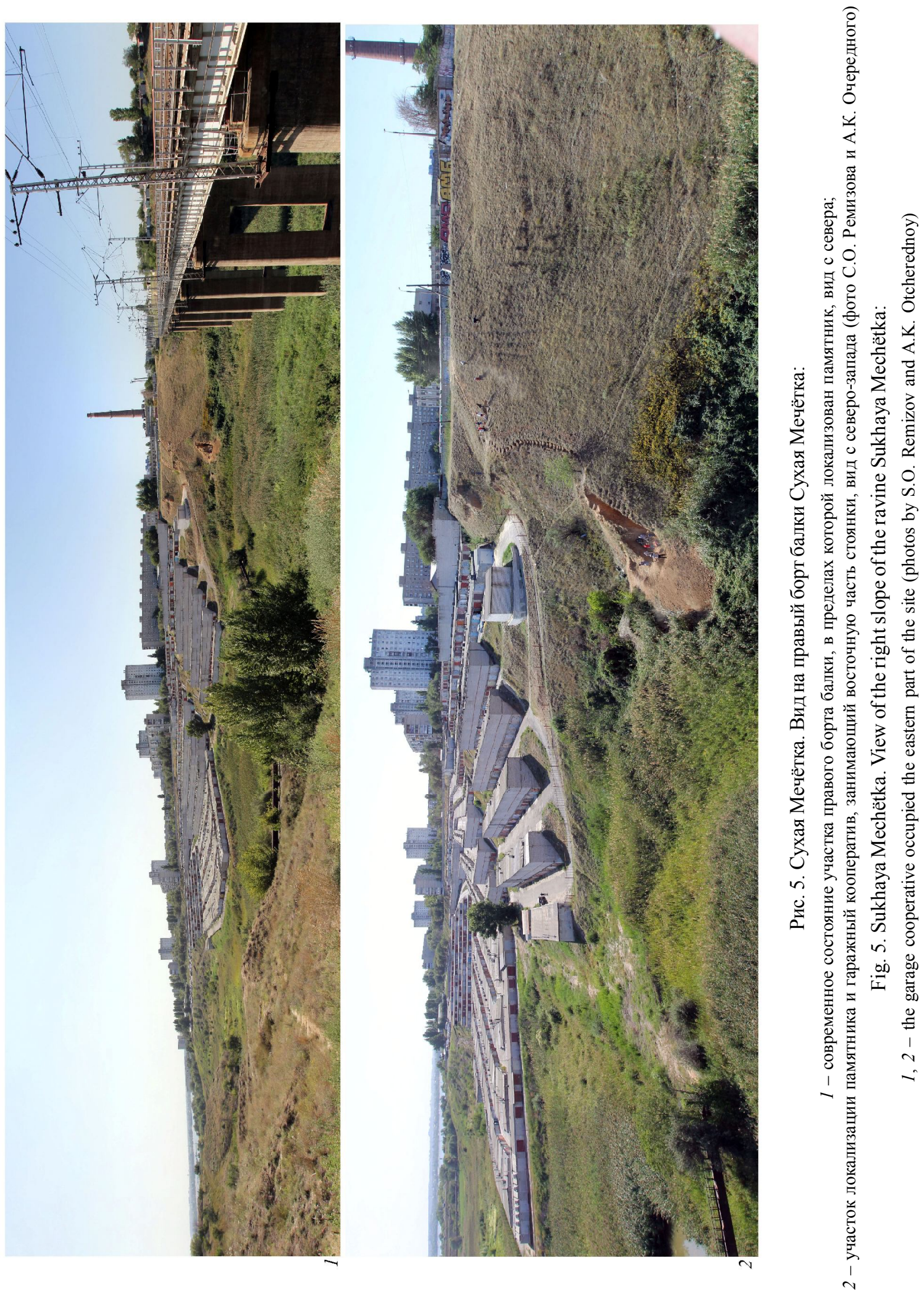
Среднепалеолитический памятник Сухая Мечётка: возобновление комплексных исследований
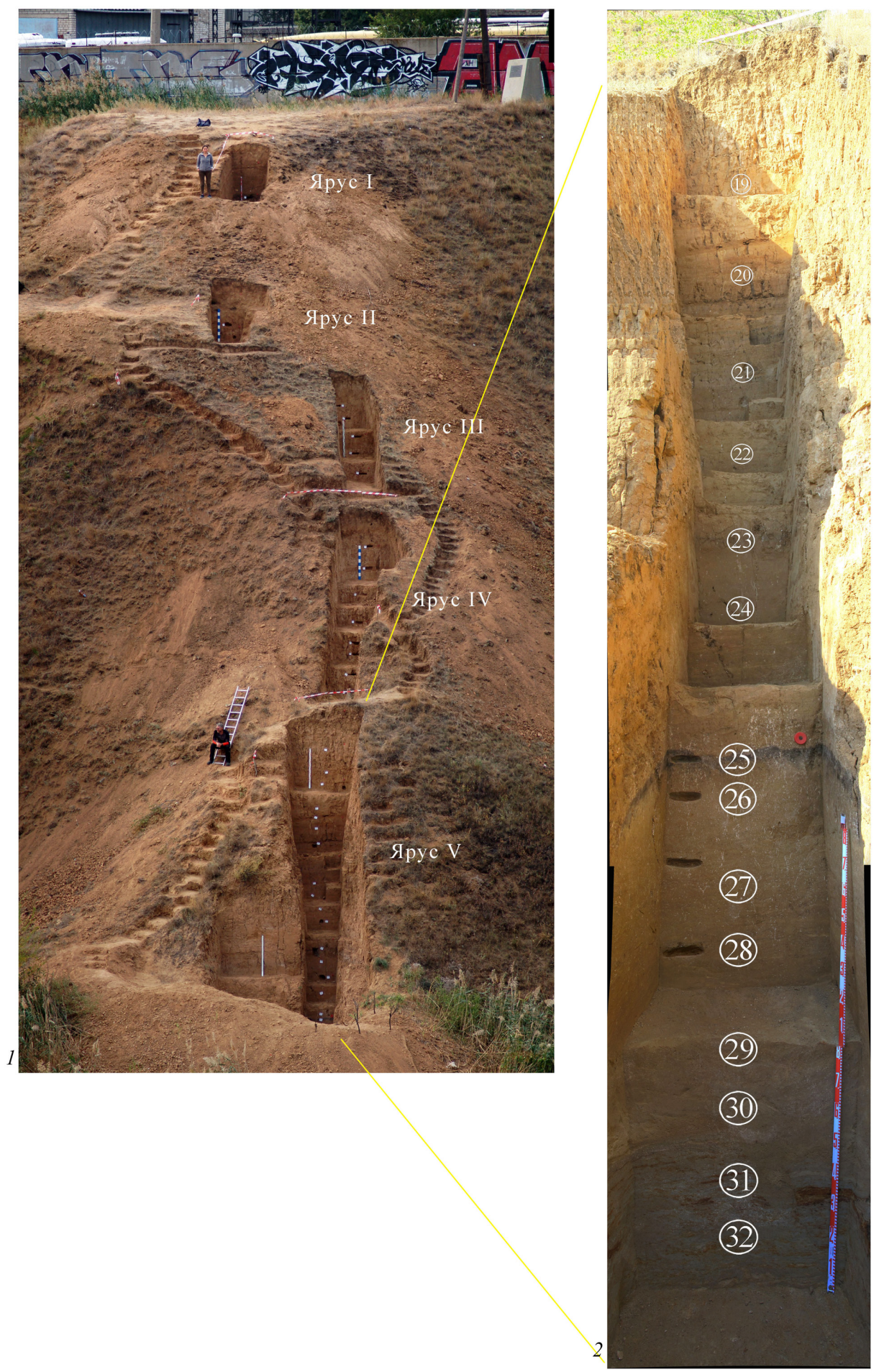

Рис. 6. Сухая Мечётка. Разрез СМ 14-18. Строение Разреза, разделенного на четыре отдельных яруса, и нижний ярус Разреза (Ярус V) с обозначением отдельных литологических слоев согласно номенклатуре описания 2018 года:

1 - Разрез СМ 14-18, вид с севера, с противоположного борта балки; 2 - Ярус V Разреза СM 14-18 (фото С.О. Ремизова и А.К. Очередного)

Fig. 6. Sukhaya Mechëtka. The Section SM 14-18. The structure of the Section, divided into four separate storeys, and the lower layer of the Section (Storey V) with the designation of lithological layers according to the nomenclature of the description of 2018 :

1 - Section SM 14-18, view from the north, from the opposite side of the ravine; 2 - Storey V of the Section SM 14-18 (photos by S.O. Remizov and A.K. Otcherednoy) 

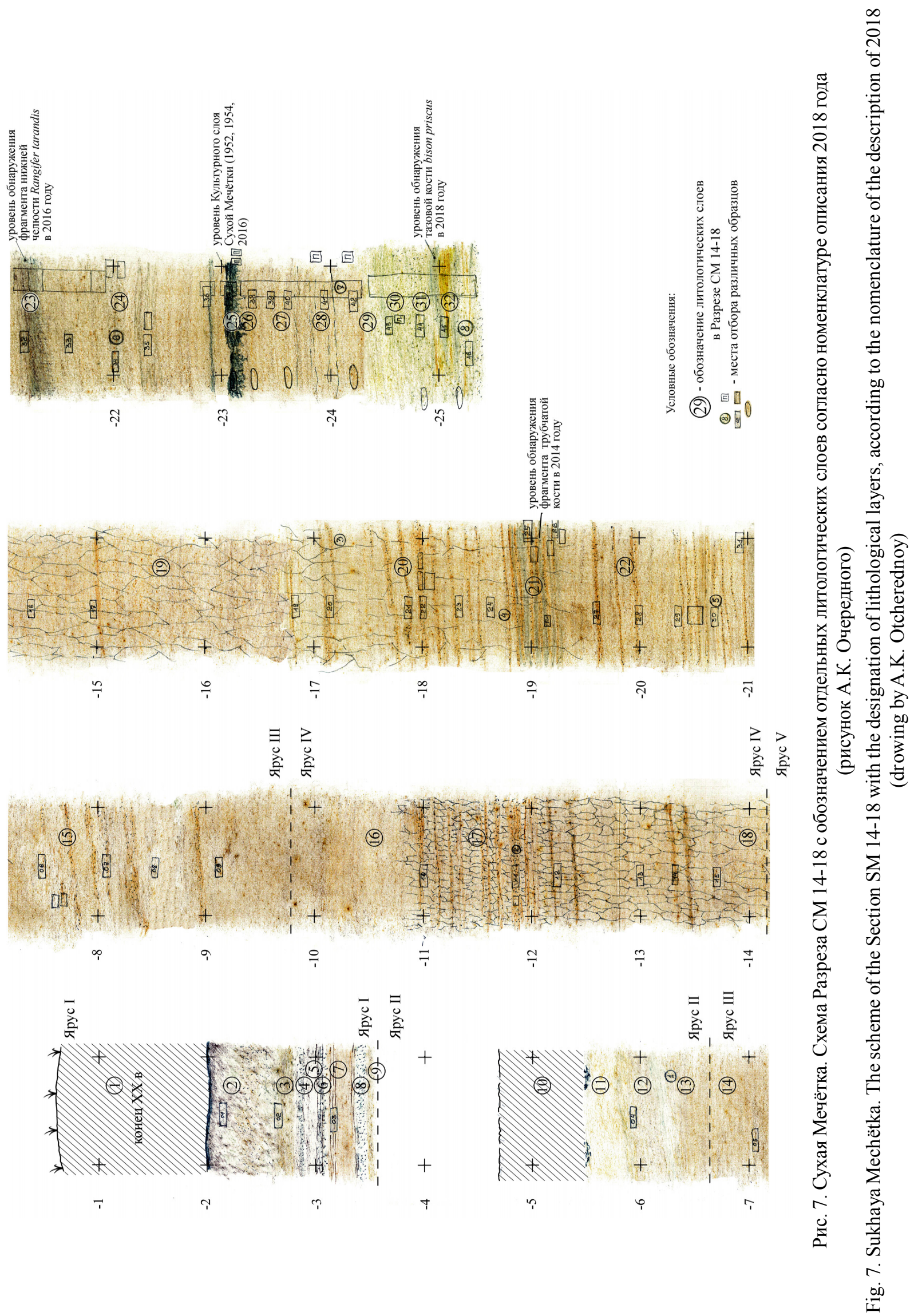


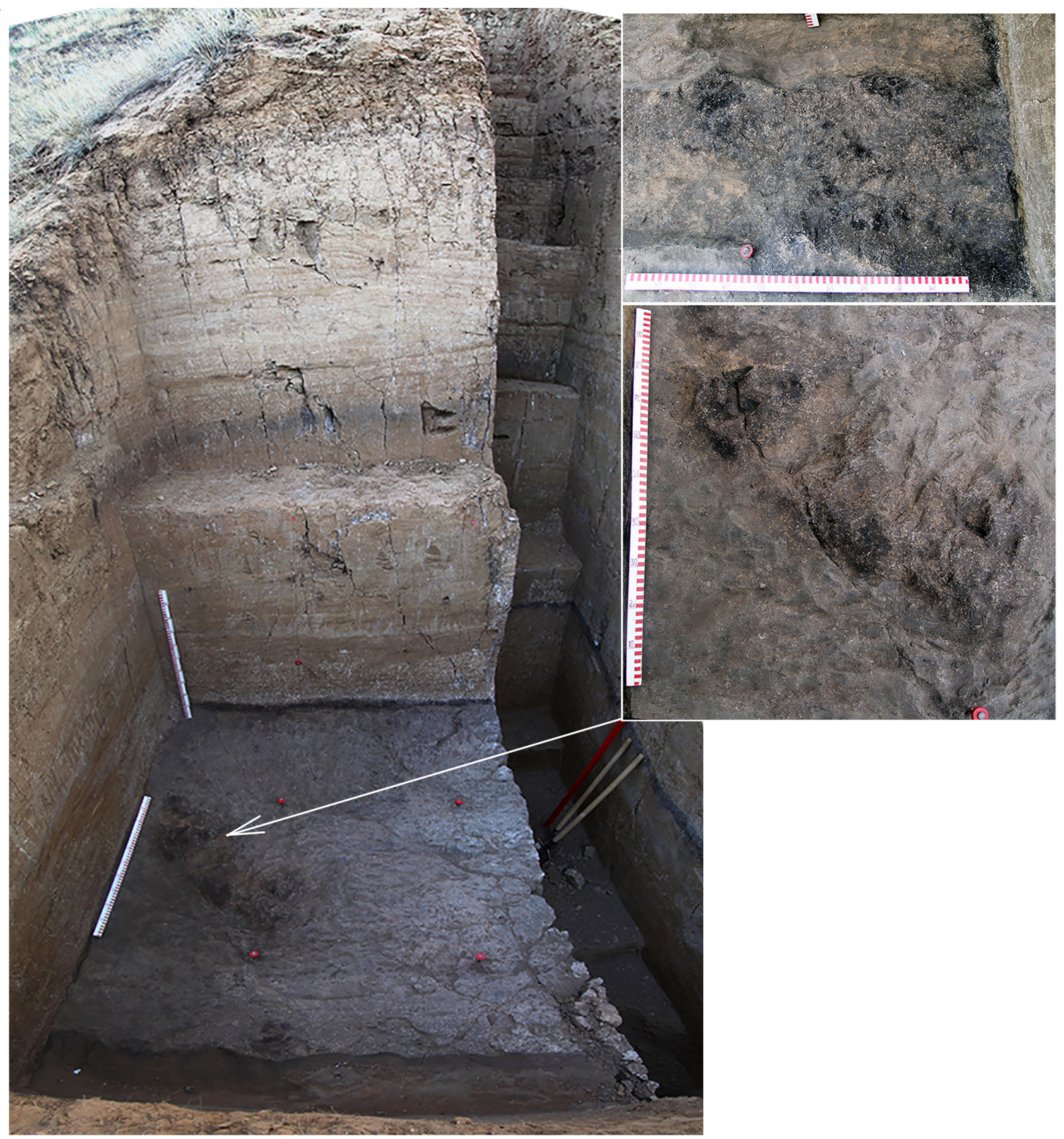

Рис. 8. Сухая Мечётка. Поверхность нижней погребенной почвы (литологический слой 25) на площади прирезки и золисто-углистые скопления (фото А.К. Очередного)

Fig. 8. Sukhaya Mechëtka. The surface of the lower buried soil (lithological layer 25) in the 2015 Trench and coals accumulation areas (photo by A.K. Otcherednoy) 

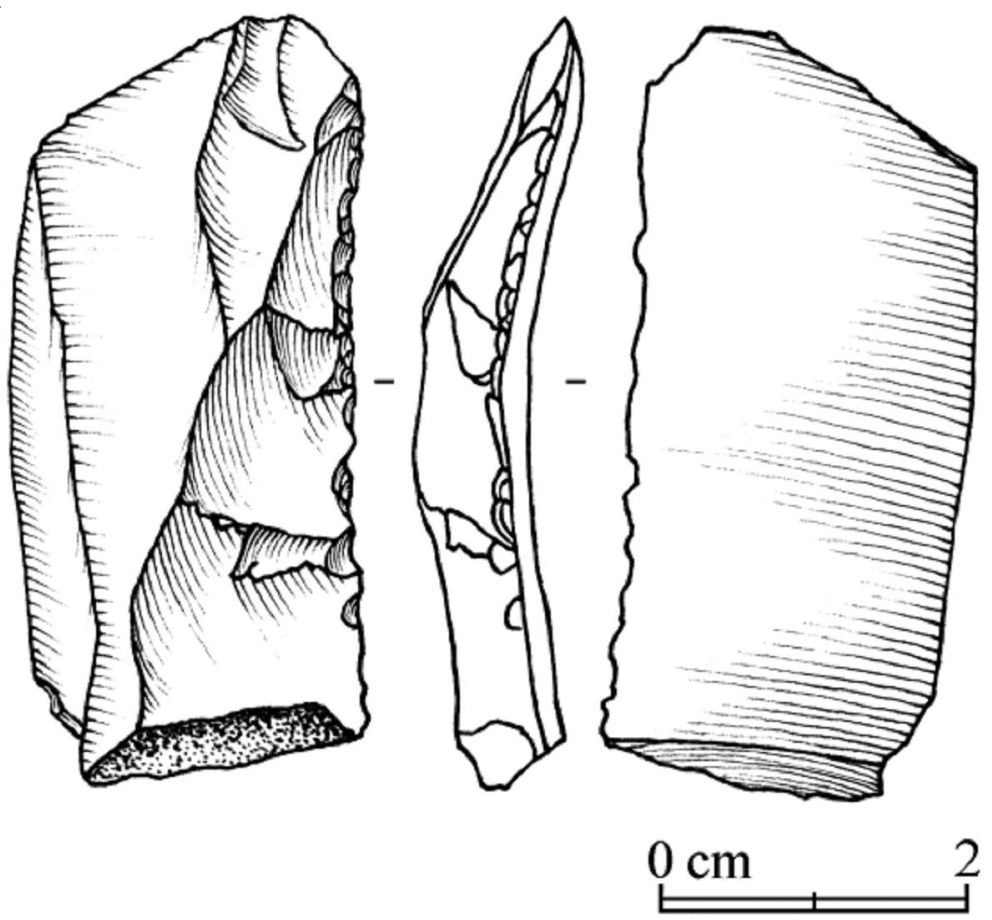

Рис. 9. Сухая Мечётка. Скол «второго снятия» (enlèvement deux) с ретушью из вскрытого отвала Раскопа 1 1954 г. рядом с Разрезом СМ 14-18 (рисунок А.К. Очередного)

Fig. 9. Sukhaya Mechëtka. Enlèvement deux flake with retouch from the dump of 1954 excavation company (drowing by A.K. Otcherednoy) 

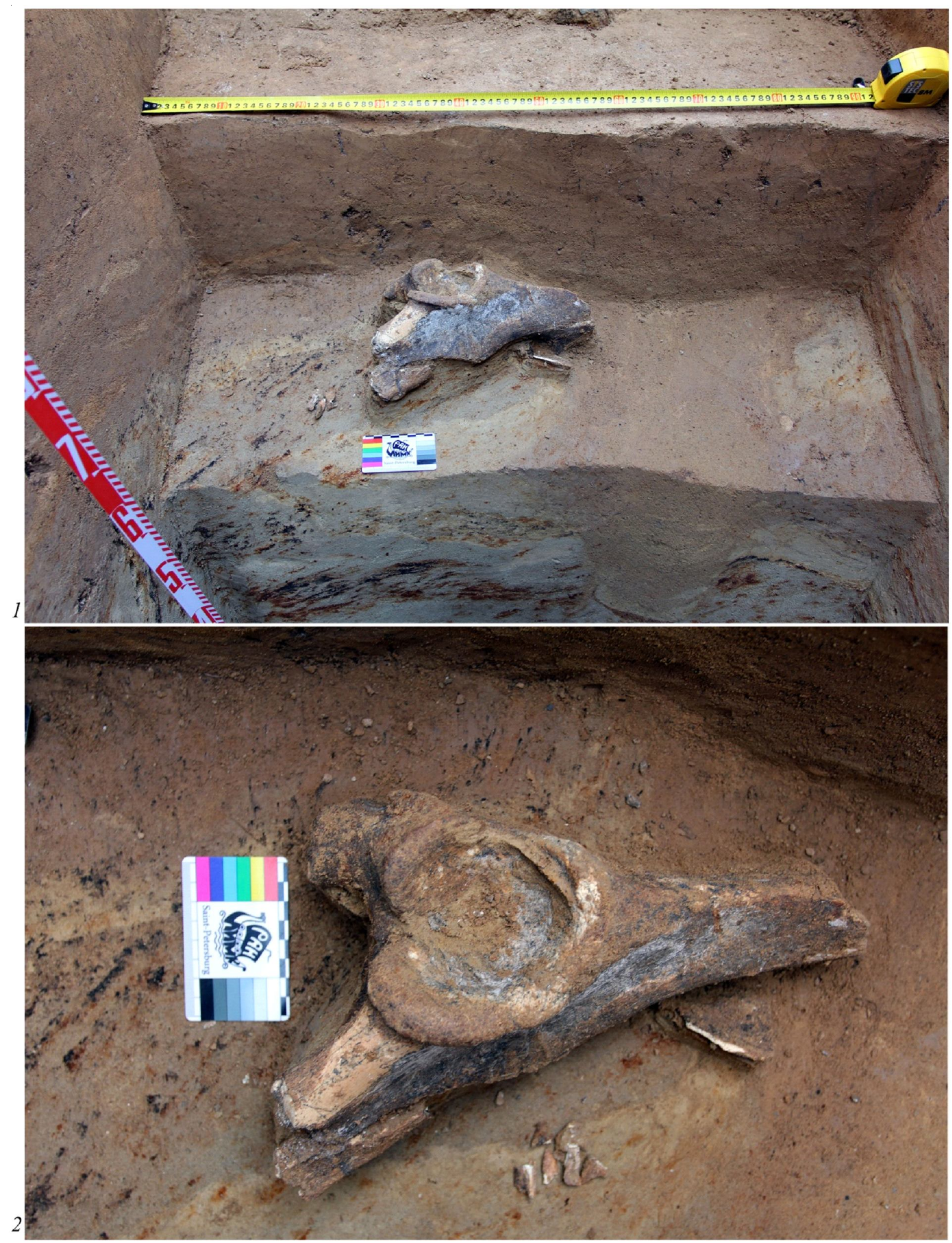

Рис. 10. Сухая Мечётка. Разрез СM 14-18. Положение тазовой кости бизона (bison priscus) в оглеенном сизом прослое ожелезненных песков (литологический слой 32) (фото А.К. Очередного)

Fig. 10. Sukhaya Mechëtka. The Section SM 14-18. The position of the pelvic bone of a bison (bison priscus) in a gleyed sands (lithological layer 32) (photo by A.K. Otcherednoy) 
Middle Paleolithic Site Sukhaya Mechëtka: the Renewal of Complex Investigations

\section{СПИСОК ЛИТЕРАТУРЫ}

Бадюкова Е. Н., 2015. История колебаний уровня Каспийского моря в плейстоцене (была ли великая Хвалынская трансгрессия?) // Бюллетень Комиссии по изучению четвертичного периода. № 74. С. 111-120.

Безродных Ю. П., Сорокин В. М., Янина Т. А., 2015. Об ательской регрессии Каспийского моря // Вестник Московского университета. Серия 5, География. № 2. С. 77-85.

Вишняцкий Л. Б., Нехорошев П. Е., Очередной А. К., 2019. Новые данные по хронологии среднего палеолита Восточной Европы (по результатам полевых исследований ИИМК РАН 1998-2018 гг.) // Прошлое человечества в трудах петербургских археологов на рубеже тысячелетий : (К 100-летию создания российской академической археологии). СПб. : Петербургское Востоковедение. С. 69-82.

Громов В. И., 1961. Геологический возраст Сталинградской стоянки // Краткие сообщения Института археологии. Вып. 82. С. 42-48.

Замятнин С. Н., 1961. Сталинградская палеолитическая стоянка // Краткие сообщения Институга археологии. Вып. 82. С. 5-37.

Кузнецова Л. В., 2000. Палеолит // История Самарского Поволжья с древнейших времен до наших дней. Каменный век. Самара : Изд-во Самар. науч. центра РАН. С. 5-80.

Кузнецова Л. В., 2006. Сухая Мечётка // Археология Нижнего Поволжья. Т. 1. Каменный век. Волгоград : Волгогр. науч. изд-во. С. 18-22.

Лаврушин Ю. А., Спиридонова Е. А., Тудрин А., Шали Ф., Антипов М. П., Кураленко Н. П., Курина Е. Е., Тухолка П., 2014. Каспий: гидрологические события позднего квартера // Бюллетень Комиссии по изучению четвертичного периода. № 73. С. 19-51.

Очередной А. К., Воскресенская Е. В., Степанова К. Н., Вишняцкий Л. Б., Нехорошев П. Е., Ларионова А. В., Зарецкая Н. Е., Блохин Е. К., Колесник А. В., 2018. Комплексные геоархеологические исследования среднепалеолитических памятников Русской равнины // Записки Института истории материальной культуры. № 17. С. 74-84. DOI: 10.31600/2310-6557-2018-17-74-83.

Праслов Н. Д., 1984. Ранний палеолит Русской равнины и Крыма // Палеолит СССР. Археология СССР. Т. 1. М. : Наука. С. 94-134.

Праслов Н. Д., Кузнецова Л. В., 2020. Палеолитическое поселение Сухая Мечётка (по материалам раскопок С. Н. Замятнина). СПб. : Невская книжная типография. 144 с.

Ремизов С. О., 2019. Исследование памятников палеолита и мезолита в бассейне Волги на территории Волгоградской области // Записки Институга истории материальной культуры. № 20. С. 174-191. DOI: 10.31600/ 2310-6557-2019-20-174-191.

Свиточ А. А., 2008. Хвалынская трансгрессия Каспия и Новоэвксинский водоем Черного моря // Водные ресурсы. Т. 35, № 2. С. 175-180.

Свиточ А. А., 2015. Палеогеография Большого Каспия // Вестник Московского университета. Серия 5, География. № 4. С. 69-80.

Салтыков В. Ф., 2011. Стратиграфическая схема плейстоцена Североприкаспийской провинции // Бюллетень Комиссии по изучению четвертичного периода. № 71. С. 95-111.

Чигуряева А. А., Хвалина Н. Я., 1961. О характере растительности в районе Сталинграда в эпоху среднего палеолита // Краткие сообщения Институга археологии. Вып. 82. С. 37-41.

Янина Т. А., 2012. Неоплейстоцен Понто-Каспия: биостратиграфия, палеогеография, корреляция. М. : Географический факультет МГУ. 264 с.

Янина Т. А., Сорокин В. М., Безродных Ю. П., Романюк Б. Ф., 2014. Гирканский этап в плейстоценовой истории Каспийского моря // Вестник Московского университета. Серия 5, География. № 3. С. 3-9.

Янина Т. А., Свиточ А. А., Курбанов Р. Н., Мюррей А. С., Ткач Н. Т., Сычев Н. В., 2017. Опыт датирования плейстоценовых отложений Нижнего Поволжья методом оптически стимулированной люминесценции // Вестник Московского университета. Серия 5, География. № 1. С. 20-28.

Bosinski G., 1967. Die mittelpaläolithischen Funde im westlichen Mitteleuropa. Fundamenta. A/4. Köln : Verlag Böhlau. $205 \mathrm{~S}$.

Kurbanov R., Yanina T., Murray A., Belyaev V., Solodovnikov D., Rogov V., Streleskaya I., Otcherednoy A., Makeev A., Lebedeva M., Rusakov A., Taratunina N., Semikolennykh D., Yarovaya S., 2018. Field trip guide Loessfest 
2018 "Diversity of loess: properties, stratigraphy, origin and regional features" September 23-29, 2018, Volgograd, Russia. Volgograd: VolGU. 64 p.

Otcherednoy A. K., Voskresenskaya E. V., Stepanova K. N., Vishnyatsky L. B., Nehoroshev P. E., Kolesnik A. V., Zaretskaya N. E., Larionova A. V., Blochin E. K., 2019. Etudes géoarchéologiques pluridisciplinaires des sites du paléolithique moyen de la Plaine Russe // L'Anthropologie. Vol. 123, № 2. P. 310-318. DOI: http://doi.org/ 10.1016/j.anthro.2019.06.005.

\section{REFERENCES}

Badyukova E.N., 2015. Istoriya kolebaniy urovnya Kaspiyskogo morya v pleystotsene (byla li velikaya Khvalynskaya transgressiya?) [The History of the Caspian Sea Level Fluctuations in the Pleistocene (Did the Great Khvalynian Transgression Really Exist?)]. Byulleten' Komissii po izucheniyu chetvertichnogo perioda [Bulletin of the Commission for Study of the Quaternary], no. 74, pp. 111-120.

Bezrodnykh Yu.P., Sorokin V.M., Yanina T.A., 2015. Ob atel'skoy regressii Kaspiyskogo morya [About the Atelian Regression of the Caspian Sea]. Vestnik Moskovskogo universiteta. Seriya 5. Geografiya [Moscow University Bulletin. Series 5. Geography], no. 2, pp. 77-85.

Vishnyatskiy L.B., Nekhoroshev P.E., Ocherednoy A.K., 2019. Novyye dannyye po khronologii srednego paleolita Vostochnoy Evropy (po rezul'tatam polevykh issledovaniy IIMK RAN 1998-2018 gg.) [New Data on the Chronology of the Middle Paleolithic of Eastern Europe (Based on the Results of Fieldwork of the Institute for the Material Culture History in 1998 to 2018)]. Proshloye chelovechestva v trudakh peterburgskikh arkheologov na rubezhe tysyacheletiy: (K 100-letiyu sozdaniya rossiyskoy akademicheskoy arkheologii) [The Past of Humankind as Seen by the Petersburg Archaeologists at the Dawn of the Millenium (to the Centennial of the Russian Academic Archaeology)]. Saint Petersburg, Peterburgskoye Vostokovedeniye Publ., pp. 69-82.

Gromov V.I., 1961. Geologicheskiy vozrast Stalingradskoy stoyanki [Geological Age of the Site Stalingradskaya]. Kratkiye soobshcheniya Instituta arkheologii [Brief Communications from the Institute of Archeology], vol. 82, pp. $42-48$.

Zamyatnin S.N., 1961. Stalingradskaya paleoliticheskaya stoyanka [Stalingradskaya Palaeolithic site]. Kratkiye soobshcheniya Instituta arkheologii [BriefCommunications from the Institute of Archeology], vol. 82, pp. 5-37.

Kuznetsova L.V., 2000. Paleolit [The Palaeolithic Period]. Istoriya Samarskogo Povolzh'ya s drevneyshikh vremen do nashikh dney. Kamennyy vek [The History of Samara Volga Region from the Ancient Times to the Present Day]. Samara, Samara Scientific Center RAS, pp. 5-80.

Kuznetsova L.V., 2006. Sukhaya Mechëtka [The Site of Suhaya Mechëtka]. Arkheologiya Nizhnego Povolzh'ya. T. 1. Kamennyy vek [The Archaeology of Lower Don Basin. Vol. 1. The Stone Age]. Volgograd, Volgogr. nauch. izd-vo Publ., pp. 18-22.

Lavrushin Yu.A., Spiridonova E.A., Tudrin A., Shali F., Antipov M.P., Kuralenko N.P., Kurina E.E., Tukholka P., 2014. Kaspiy: gidrologicheskiye sobytiya pozdnego kvartera [The Caspian Sea: hydrological events of the late Quaternary]. Byulleten Komissii po izucheniyu chetvertichnogo perioda [Bulletin of the Commission for Study of the Quaternary], no. 73, pp. 19-51.

OcherednoyA.K., Voskresenskaya E.V., Stepanova K.N., Vishnyatskiy L.B., Nekhoroshev P.E., Larionova A.V., Zaretskaya N.E., Blokhin E.K., KolesnikA.V., 2018. Kompleksnyye geoarkheologicheskiye issledovaniya srednepaleoliticheskikh pamyatnikov Russkoy ravniny [Complex Geoarhaeological Studies of the Middle Paleolithic Sites in the Russian Plain]. Zapiski Instituta istorii material'noy kul'tury [Transactions of the Institute for the History of Material Culture], no. 17, pp. 74-84. DOI: https://doi.org/10.31600/2310-6557-2018-17-74-83.

Praslov N.D., 1984. Ranniy paleolit Russkoy ravniny i Kryma [Early Palaeolithic of Russian Plain and Crimea]. Paleolit SSSR. Arkheologiya SSSR [Palaeolithic of USSR. Archaeology of USSR], vol. 1. Moscow, Nauka Publ., pp. 94-134.

Praslov N.D., Kuznetsova L.V., 2020. Paleoliticheskoye poseleniye Sukhaya Mechëtka (po materialam raskopok S.N. Zamyatnina) [Sukhaya Mechëtka, a Paleolithic Site (on the Data of S.N. Zamyatnin's Excavations)]. Saint Petersburg, Nevskaya knizhnaya tipografiya Publ. 144 p. (in Russian).

Remizov S.O., 2019. Issledovaniye pamyatnikov paleolita i mezolita v basseyne Volgi na territorii Volgogradskoy oblasti [Paleolithic and Mesolithic Sites in the Volga Basin on the Territory of Volgograd Oblast]. Zapiski Instituta istorii material'noy kul'tury [Transactions of the Institute for the History of Material Culture], no. 20, pp. 174-191. DOI: https://doi.org/10.31600/2310-6557-2019-20-174-191. 
Middle Paleolithic Site Sukhaya Mechëtka: the Renewal of Complex Investigations

Svitoch A.A., 2008. Khvalynskaya transgressiya Kaspiya i Novoevksinskiy vodoyem Chernogo morya [Khvalynsk Transgression of the Caspian Sea and Novoeevksinsky Reservoir of the Black Sea]. Vodnyye resursy [Water Resources], vol. 35, no. 2, pp. 175-180.

Svitoch A.A., 2015. Paleogeografiya Bol'shogo Kaspiya [Paleogeography of the Greater Caspian Sea]. Vestnik Moskovskogo universiteta. Seriya 5. Geografiya [Moscow University Bulletin. Series 5. Geography], no. 4, pp. 69-80.

Saltykov V.F. 2011. Stratigraficheskaya skhema pleystotsena Severoprikaspiyskoy provintsii [Stratigraphic Diagram of the Pleistocene of the North Caspian Province]. Byulleten' Komissii po izucheniyu chetvertichnogo perioda [Bulletin of the Commission for Study of the Quaternary], no. 71, pp. 95-111.

Chiguryayeva A.A., Khvalina N.Ya., 1961. O kharaktere rastitel'nosti v rayone Stalingrada v epokhu srednego paleolita [On the Characteristic of Vegetation in the Stalingrad Region During the Middle Palaeolithic]. Kratkiye soobshcheniya Instituta arkheologii [Brief Communications from the Institute of Archeology], vol. 82, pp. 37-41.

Yanina T.A., 2012. Neopleystotsen Ponto-Kaspiya: biostratigrafiya, paleogeografiya, korrelyatsiya [Neopleistocene of the Ponto-Caspian: Stratigraphy, Paleogeography, Correlation]. Moscow, Faculty of Geography, Moscow State University. 264 p.

Yanina T.A., Sorokin V.M., Bezrodnykh Yu.P., Romanyuk B.F., 2014. Girkanskiy etap v pleystotsenovoy istorii Kaspiyskogo morya [The Girkan Stage in the Pleistocene History of the Caspian Sea]. Vestnik Moskovskogo universiteta. Seriya 5. Geografiya [Moscow University Bulletin. Series 5. Geography], no. 3, pp. 3-9.

Yanina T.A., Svitoch A.A., Kurbanov R.N., Myurrey A.S., Tkach N.T., Sychev N.V., 2017. Opyt datirovaniya pleystotsenovykh otlozheniy Nizhnego Povolzhia metodom opticheski stimulirovannoy lyuminestsentsii [Paleogeographic Analysis of the Results of Optically Stimulated Luminescence Dating of Pleistocene Deposits of the Lower Volga Area]. Vestnik Moskovskogo universiteta. Seriya 5. Geografiya [Moscow University Bulletin. Series 5. Geography], no. 1, pp. 20-28.

Bosinski G., 1967. Die mittelpaläolithischen Funde im westlichen Mitteleuropa. Fundamenta. A/4. Köln, Verlag Böhlau. $205 \mathrm{~S}$.

Kurbanov R., Yanina T., Murray A., Belyaev V., Solodovnikov D., Rogov V., Streleskaya I., Otcherednoy A., Makeev A., Lebedeva M., Rusakov A., Taratunina N., Semikolennykh D., Yarovaya S., 2018. Field Trip Guide Loessfest 2018 "Diversity of Loess: Properties, Stratigraphy, Origin and Regional Features" September 23-29, 2018, Volgograd, Russia. Volgograd, VolGU. 64 p.

Otcherednoy A.K., Voskresenskaya E.V., Stepanova K.N., Vishnyatsky L.B., Nehoroshev P.E., Kolesnik A.V., Zaretskaya N.E., Larionova A.V., Blochin E.K., 2019. Etudes géoarchéologiques pluridisciplinaires des sites du paléolithique moyen de la Plaine Russe, L'Anthropologie, vol. 123, no. 2, pp. 310-318. DOI: http://doi.org/ 10.1016/j.anthro.2019.06.005.

\section{Information About the Authors}

Aleksander K. Otcherednoy, Candidate of Sciences (History), Senior Researcher, Paleolithic Department, Institute for the History of Material Culture RAS, Dvortsovaya emb., 18, 191186 Saint Petersburg, RussianFederation, mr_next@rambler.ru, a.otcherednoy@gmail.com, https:/orcid.org/0000-0001-7616-5686

Stanislav O. Remizov, Historical, Ethnographic and Architectural Museum-Preserve "Old Sarepta", Volgograd, Russian Federation, Izobilnaya St., 10, 400026 Volgograd, Russian Federation, paleostas@yandex.ru, https://orcid.org/0000-0001-9892-8058

Ksenia N. Stepanova, Candidate of Sciences (History), Researcher, Paleolithic Department, Institute for the History of Material Culture RAS, Dvortsovaya emb., 18, 191186 Saint Petersburg, Russian Federation,ksstepan@gmail.com, https://orcid.org/0000-0002-2814-2639

Maxim V. Eltsov, Candidate of Sciences (Biology), Institute of Physicochemical and Biological Problems in Soil Science RAS, Institutskaya St., 2, 142290 Pushchino, Russian Federation, m.v.eltsov@gmail.com, https://orcid.org/0000-0001-7886-8131

Ekaterina V. Voskresenskaya, Researcher, Quaternary paleogeography Department, Institute of geography RAS, Khvostov pereulok, 29, 119017 Moscow, Russian Federation, kavosk@mail.ru, https://orcid.org/ 0000-0003-1874-2697 
Leonid B. Vishnyatsky, Doctor of Sciences (History), Leading Researcher, Paleolithic Department, Institute for the History of Material Culture RAS, Dvortsovaya emb., 18, 191186 Saint Petersburg, Russian Federation, lvishn@yandex.ru, https://orcid.org/0000-0003-3069-5715

Pavel E. Nehoroshev, Candidate of Sciences (History), Senior Researcher, Paleolithic Department, Institute for the History of Material Culture RAS, Dvortsovaya emb., 18, 191186 Saint Petersburg, Russian Federation, paleolithic@narod.ru,https://orcid.org/0000-0001-6634-9211

Egor K. Blochin, Researcher, Rescue archeology Department, Institute for the History of Material Culture RAS, Dvortsovaya emb., 18, 191186 Saint Petersburg, Russian Federation, jegor.blochin@gmail.com, https://orcid.org/0000-0002-8190-7741

Vadim V. Titov, Candidate of Sciences (Biology), Leading Researcher, Southern Scientific Center of the RAS, Prosp. Chekhova, 41, 344006 Rostov-on-Don, Russian Federation, vvtitov@yandex.ru, https://orcid.org/0000-0001-5938-5775

Aleksander V. Kolesnik, Doctor of Sciences (History), Professor, Head Department of Historiography, Source Studies, Archeology and Methods of Teaching History, Donetsk National University, Universitetskaya St., 24, 283001 Donetsk, Ukraine, akolesnik2007@mail.ru, https://orcid.org/0000-0002-4933-8438

\section{Информация об авторах}

Александр Константинович Очередной, кандидат исторических наук, старший научный сотрудник, Отдел палеолита, Институт истории материальной культуры РАН, Дворцовая набережная, 18, 191186 г. Санкт-Петербург, Российская Федерация, mr_next@rambler.ru, a.otcherednoy@gmail.com, https://orcid.org/0000-0001-7616-5686

Станислав Олегович Ремизов, научный сотрудник, Историко-этнографический и архитектурный музей-заповедник «Старая Сарепта», ул. Изобильная, 10, 400026 г. Волгоград, Российская Федерация, paleostas@yandex.ru, https://orcid.org/0000-0001-9892-8058

Ксения Николаевна Степанова, кандидат исторических наук, научный сотрудник, Отдел палеолита, Институт истории материальной культуры РАН, Дворцовая набережная, 18, 191186 г. Санкт-Петербург, Российская Федерация, ksstepan@gmail.com, https://orcid.org/0000-0002-2814-2639

Максим Витальевич Ельцов, кандидат биологических наук, старший научный сотрудник, лаборатория археологического почвоведения, Институт физико-химических и биологических проблем почвоведения РАН, ул. Институтская, 2, 142290 г. Пущино, Российская Федерация, m.v.eltsov@gmail.com, https://orcid.org/0000-0001-7886-8131

Екатерина Владимировна Воскресенская, научный сотрудник, Отдел палеогеографии четвертичного периода, Институт географии РАН, Старомонетный пер., 29, 119017 г. Москва, Российская Федерация, kavosk@mail.ru, https://orcid.org/0000-0003-1874-2697

Леонид Борисович Вишняцкий, доктор исторических наук, ведущий научный сотрудник, Отдел палеолита, Институт истории материальной культуры РАН, Дворцовая набережная, 18, 191186 г. Санкт-Петербург, Российская Федерация, lvishn@yandex.ru, https://orcid.org/0000-0003-3069-5715

Павел Евгеньевич Нехорошев, кандидат исторических наук, старший научный сотрудник, Отдел палеолита, Институт истории материальной культуры РАН, Дворцовая набережная, 18, 191186 г. Санкт-Петербург, Российская Федерация, paleolithic@narod.ru, https://orcid.org/0000-0001-6634-9211

Егор Константинович Блохин, научный сотрудник, Отдел охранной археологии, Институт истории материальной культуры РАН, Дворцовая набережная, 18, 191186 г. Санкт-Петербург, Российская Федерация, jegor.blochin@gmail.com, https://orcid.org/0000-0002-8190-7741

Вадим Владимирович Титов, кандидат биологических наук, главный научный сотрудник, Лаборатория палеогеографии, Южный научный центр РАН, просп. Чехова, 41, 344006 г. Ростовна-Дону, Российская Федерация, vvtitov@yandex.ru, https://orcid.org/0000-0001-5938-5775

Александр Викторович Колесник, доктор исторических наук, профессор, заведующий кафедрой историографии, источниковедения, археологии и методики преподавания истории, Донецкий национальный университет, ул. Университетская, 24, 283001 г. Донецк, Украина, akolesnik2007@mail.ru, https://orcid.org/0000-0002-4933-8438 